IdeAs

Idées d'Amériques

$3 \mid 2012$

L'alimentation dans les Amériques au prisme des sciences sociales

\title{
La alimentación: cuestiones teóricas y empíricas en las Américas
}

L'alimentation: enjeux théoriques et empiriques dans les Amériques

Theoretical and empirical aspects to food in North and South America

Philippe Cardon y Domingo Garcia-Garza

Traductor: Marta Gómez

\section{OpenEdition}

Journals

Edición electrónica

URL: https://journals.openedition.org/ideas/2294

DOI: $10.4000 /$ ideas.2294

ISSN: 1950-5701

Este artículo es una traducción de:

L'alimentation : enjeux théoriques et empiriques dans les Amériques - URL : https:// journals.openedition.org/ideas/403 [fr]

Otras traducciones del artículo:

Theoretical and empirical aspects to food in North and South America - URL : https:// journals.openedition.org/ideas/2293 [en]

A alimentação: questões teóricas e empíricas nas Américas - URL : https://journals.openedition.org/ ideas/3139 [pt]

Editor

Institut des Amériques

Referencia electrónica

Philippe Cardon y Domingo Garcia-Garza, «La alimentación: cuestiones teóricas y empíricas en las Américas», IdeAs [En línea], 3 | 2012, Publicado el 10 diciembre 2012, consultado el 18 octubre 2022. URL: http://journals.openedition.org/ideas/2294 ; DOI: https://doi.org/10.4000/ideas.2294

Este documento fue generado automáticamente el 18 octubre 2022

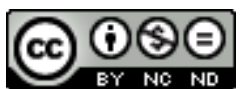

Creative Commons - Atribución-NoComercial-SinDerivadas 4.0 Internacional - CC BY-NC-ND 4.0 https://creativecommons.org/licenses/by-nc-nd/4.0/ 


\title{
La alimentación: cuestiones teóricas y empíricas en las Américas
}

\author{
L'alimentation: enjeux théoriques et empiriques dans les Amériques \\ Theoretical and empirical aspects to food in North and South America
}

Philippe Cardon y Domingo Garcia-Garza

Tradución : Marta Gómez

1 La alimentación se ha tratado de forma marginal en los estudios sobre las sociedades de América del Sur. Por el contrario, en Estados Unidos y Canadá, así como en Europa, la investigación sobre la alimentación ha tenido mayor desarrollo. Este tercer número temático de la revista IdeAs pretende colmar estas lagunas y relanzar una reflexión olvidada por mucho tiempo o abandonada por las ciencias sociales, pero que sigue formando parte del imaginario y de la realidad a ambos lados del Atlántico. El otro objetivo de este dossier es lanzar una mirada interdisciplinar sobre la alimentación a escala continental desde un punto de vista sociológico, antropológico e histórico.

2 «Hecho social total», la alimentación ofrece efectivamente un ángulo privilegiado para estudiar las sociedades. Los historiadores y antropólogos están entre los primeros en interesarse por la cuestión. Del lado europeo, los trabajos de Claude Lévi-Strauss (1964) y Fernand Braudel (1967), así como de Jean-Louis Flandrin y Massimo Montanari (1996), abrieron el camino a fructíferos proyectos de investigación. Del lado estadounidense, los historiadores (Garnsey, 1999; Gabaccia, 1998; Bauer, 2001) y los antropólogos (Douglas, 1965; Goody, 1982; Mintz, 1996; Mintz y Dubois, 2002) se han convertido en referentes en este tema. Las investigaciones sobre la cuestión alimentaria llevadas a cabo en América Latina o las que se han publicado en español o portugués han privilegiado la perspectiva histórica (Freyre, 1933; Cascudo, 1983; Flores, 2003; Fernández-Armesto, 2004; Magalhães, 2004; Bourgues et al., 2009), antropológica (Vargas, 1993; Ortiz et al., 2004; Contreras y Gracia, 2005; Carrasco, 2007; Bertrán, 2010), e incluso pluridisciplinar (Oseguera, 2003; Long-Solis y Vargas, 2005). Estos estudios se centran básicamente en las dimensiones folclóricas, simbólicas o identitarias y 
regionales de la alimentación, o en las prácticas de grupos minoritarios (de Suremain y Katz, 2009).

3 Las diversas colaboraciones reunidas en este tercer dossier temático de la revista IdeAs sobre la alimentación en las sociedades americanas (mundos anglosajón e hispánico) proponen una lectura sociológica, antropológica e histórica del hecho alimentario. En primer lugar, estudian la alimentación como marcador de identidad, tanto identidad de diferentes grupos sociales como identidad nacional, a veces nacionalista, de los países latinoamericanos o del norte de las Américas. Los estudios abordan particularmente los fenómenos de distinción social, la invención de una «tradición alimentaria» e incluso la «fabricación» de una alimentación que se inscribe en un discurso nacional, si no nacionalista. Otros artículos se centran en la producción y el consumo de alimentos locales y en las condiciones económicas y sociales que implica su comercialización tanto a escala local como internacional. Asimismo, hay otros estudios que analizan el papel que tiene la difusión de productos alimentarios entre países en las prácticas alimentarias de los migrantes, en especial del sur hacia el norte, abriendo la reflexión sobre los procesos de «mestizaje» que han dado lugar a las cocinas latinoamericanas. Así, si bien la alimentación persiste como un fuerte marcador de identidad (de clase y también nacional), también tiene cabida en los procesos de mestizaje alimentario y de «hibridación» de prácticas, sobre todo en el contexto de la migración. En este sentido, la cuestión de la difusión de estilos, de modas y de normas alimentarias subyace implícitamente en todos los textos, ya se trate de la difusión de nuevas normas gastronómicas entre las élites brasileñas (Carolina Pulici), de nuevas normas alimentarias «éticas» en diferentes poblaciones de Canadá (Josée Johnston et al.), de un producto de lujo difundido al conjunto de la población (Natalia Milanesio), de la difusión de prácticas populares entre las clases más favorecidas (García Garza), del modelo criollo en Argentina, Cuba y México (Jeffrey Pilcher), de prácticas alimentarias «híbridas» entre Estados Unidos y los países de Sudamérica (Maximino Matus) o bien de la difusión de las prácticas estadounidenses entre los inmigrantes mexicanos (Frida Calderón-Bony). Paralelamente, se plantea la cuestión de las condiciones sociales de apropiación de estos nuevos estilos alimentarios por parte de cada población concreta. Uno de los propósitos de este dossier temático es estudiar en qué medida las sociologías de la alimentación, especialmente prolíficas en Francia (Poulain, 2001, 2002, 2012; Corbeau, 2000; Poulain y Corbeau, 2002; Régnier et al., 2006; Fischler y Masson, 2007), son transferibles a las sociedades del continente americano.

\section{La alimentación como factor de diferenciación social}

Numerosos trabajos -ya sean estudios sobre la importancia del gasto en alimentación en el nivel de vida en México, por ejemplo (Martínez y Villezca, 2003; Torres y Trápaga, 2001), o sobre el papel que desempeña la venta de ciertos alimentos como actividad económica alternativa frente a la exclusión social en los países en desarrollo (Babb, 1987; Tinker, 1997; Chaves, 2006; García Garza, 2009)- subrayan cómo la alimentación constituye un marcador social. Estos estudios se enmarcan de forma más global en la problemática de las diferenciaciones sociales del consumo, una cuestión que los estudios europeos tratan ampliamente, especialmente la sociología francesa (Herpin y Verger, 2008) desde las primeras investigaciones de Maurice Halbwachs sobre el consumo de la clase obrera, que continuaron sus herederos, Pierre Bourdieu y Claude 
Grignon, entre otros. Éstos mostraron ampliamente la importancia de la diversidad social en el consumo alimentario que, más allá de ciertos platos o saberes culinarios regionales, nacionales o patrimoniales, está profundamente marcado por los efectos de estructura derivados de la pertenencia a un grupo social (Grignon y Grignon, 1980; Régnier et al., 2006), de la edad o el ciclo de vida (Cardon, 2010, 2009a, 2009b; Cardon y Gojard, 2009; Gojard, 2010) o de la región (Poulain, 2001). Por otro lado, la aparición de una oferta alimentaria nueva ligada al desarrollo de la industria agroalimentaria, las grandes superficies, la comida rápida y los nuevos productos (alimentos congelados, por ejemplo) no ha puesto en entredicho el mantenimiento de ciertas «culturas alimentarias locales» (Poulain, 2002). De este modo, la alimentación se considera un fuerte marcador social determinado por las prácticas propias de ciertos grupos sociales.

\section{La cuestión en torno a la distinción social}

El estudio de la estructura social del consumo se abre con el clásico análisis de los mecanismos de la distinción que desarrolla Pierre Bourdieu, entre otros, en su obra La distinción (1979), en donde defiende la tesis según la cual la posición social en el espacio social determina un estilo de vida $\mathrm{y}$, por extensión, unos gustos, en especial, alimentarios, socialmente marcados (Bourdieu, 1976). Los gustos, al ser «clasificadores», esto es, soportes de clasificación, también son marcadores de la posición social en el espacio social. En este número, Johnston, Szabo y Rodney, al igual que García Garza, ponen de manifiesto que las características sociales ejercen una influencia considerable en el consumo alimentario. Johnston et al. describen por ejemplo cómo se construye una alimentación «ética» en Canadá a partir de la observación de dos grupos sociales distintos (clases populares frente a clases favorecidas). Estos autores destacan el papel que desempeña el capital cultural, más allá del origen social, en los motivos que llevan a los consumidores a comprar productos considerados «bio» o respetuosos con el medio ambiente y la salud. Por su parte, García Garza pone de relieve cómo el proceso de ennoblecimiento de productos populares contribuye a redefinir la legitimidad de la jerarquía alimentaria en México.

6 En este número de IdeAs, diversos textos demuestran asimismo que los nuevos estilos de alimentación no hacen desaparecer necesariamente las diferencias sociales ni las relaciones simbólicas entre clases. De hecho, los nuevos hábitos alimentarios dibujan igual que antes las fronteras simbólicas entre los diferentes grupos sociales (Bourdieu, 1979; Cole, 2008). Lamont (1992), por ejemplo, muestra que las fronteras, clasificadas en tres categorías (socioeconómica, cultural y moral), pueden incluir o excluir a los miembros de una sociedad en función de su estatus, de la posesión de recursos o de sus avances sociales. Esta autora muestra la correlación entre estilos de vida y diferentes estatus sociales. Este aspecto ya había sido planteado por Bourdieu (1979) en su estudio sobre la dimensión cultural en los juegos de diferenciación social.

7 En cualquier caso, el mantenimiento de las diferenciaciones sociales, independientemente de la difusión de nuevos estilos alimentarios de un lado y de otro de la escala social, relanza el debate sobre el omnivorismo cultural (Peterson, 1992; Peterson y Kern, 1996; Duval, 2010; Coulangeon, 2011). Como cualquier otra práctica cultural, la alimentación obedece a juegos de diferenciación social en función de la posición que ocupan los individuos y los grupos en el espacio social y ello, a su vez, en función del nivel educativo y del origen sociocultural. Las prácticas culturales 
corresponden, según este esquema, a diferentes clases sociales. El comportamiento omnívoro solo se observa en las clases más favorecidas y se da cuando dichos grupos presentan un «eclecticismo informado» hacia la cultura, esto es, una diversificación cultural selectiva (Donnat, 1994; Eloy y Palheta, 2008; Eloy, 2012). En otras palabras, las prácticas culturales asociadas a un comportamiento ecléctico solo están presentes en las clases sociales altas. Además, estas prácticas se producen solo de forma puntual ya que los grupos sociales más favorecidos prefieren las prácticas culturales propias del entorno del que proceden. Asimismo, como destacan Johnston y Bauman (2007: 198), Bourdieu ya había reparado en la aparición de tendencias al omnivorismo en las personas más ricas en capital cultural que en capital económico (los profesores, en este caso) que, por ello, practicaban un consumo ascético y buscaban el «exotismo» y el «populismo culinario» (Bourdieu, 1979: 207). Los diversos textos publicados en este número de IdeAs sobre la alimentación en las Américas nos permiten medir la fuerza y la validez de las que goza la teoría de la legitimidad cultural esbozada por Bourdieu a finales de los años 70 .

\section{La apropiación de nuevos modelos alimentarios}

8 Uno de los propósitos teóricos de este número de IdeAs es por tanto dar cuenta de la apropiación social de nuevos modelos alimentarios, tales como las nuevas gastronomías, que analiza Carolina Pulici en su estudio sobre las élites brasileñas (banqueros, embajadores, coleccionistas de arte, rentistas, industriales, empresarios) o la alimentación ética, que estudian Josée Johnston y sus colegas en Canadá. Estos autores tratan de entender en qué medida y en qué condiciones sociales estos nuevos modelos se convierten o no en soportes de distinción social. Retomando la metodología de investigación iniciada por Norbert Elias en su obra La civilización de las costumbres, Caroline Pulici se centra en el análisis de manuales de buenas prácticas publicados recientemente en Brasil y de críticas gastronómicas publicadas en la prensa de São Paulo entre 2005 y 2009 con el fin de extraer las normas que en la actualidad se imponen como legítimas en materia de cocina y de modales en la mesa. La autora muestra cómo las élites se reapropian o no de estas nuevas normas alimentarias dentro de sus propias representaciones sociales y en su relación con los demás grupos, y cómo estos nuevos modelos alimentarios les permiten situarse socialmente respecto al resto, en particular, frente a las clases populares. Así, frente a una alimentación popular considerada «voraz» por las élites (la «voracidad popular» sería la expresión de los sentimientos naturales), éstas representan por el contrario una cultura alimentaria que precisamente rechaza esos elementos de percepción propios de las clases populares. Esta censura de los sentimientos naturales funciona como regla de moderación alimentaria, de contención y de sentido estético que caracterizan al estilo burgués respecto a la comida. La apropiación de esta nueva cocina gastronómica mantiene la distinción social en cuanto que contribuye a la elaboración de una representación y una ética basada en el control de sí mismo. La autora, que hace suya aquí la tesis del autocontrol desarrollada por Norbert Elias a propósito de las sociedades europeas, escribe: «mientras el 'pueblo', que tiene menos que esperar del futuro, se pierde en sensualismos, la élite demuestra el control de sí misma en todos los sentidos, tanto en el control de sus apetitos corporales como en el de sus condiciones ideales y materiales de existencia». Aquí, la alimentación, dado que está ligada a una ética de vida propia de un grupo, permite mantener y marcar distancias con otros grupos sociales y por tanto, 
diferenciarse. Por tanto, se entiende que la élite brasileña adopte fácilmente estas nuevas normas gastronómicas por cuanto éstas funcionan como un repertorio simbólico que permite distinguirse y distanciarse de los demás grupos sociales respecto a las diferentes formas de autocontrol.

Sin embargo, ¿lo que parece distinguir, diferencia siempre tanto? Esta es en esencia la cuestión que trata Josée Johnston et al. a propósito de la difusión de la alimentación considerada «ética» en la sociedad canadiense, un modelo alimentario muy bien visto por los poderes públicos ya que representa un nuevo mercado potencial del que se espera algún tipo de plusvalía sanitaria. Tomando como base una encuesta cualitativa realizada a 40 familias, las autoras buscan averiguar si la alimentación ética, que en principio estaría entre las prácticas culturales propias de las clases altas, también puede ser patrimonio de otros grupos sociales, en especial, las clases populares. Dicho de otro modo, se trata de determinar cómo el discurso sobre la alimentación ética se percibe y es puesto en práctica por consumidores que no gozan de los mismos privilegios. Las autoras distinguen dos partes en su análisis. Por un lado, buscan averiguar si existen o no diferencias de clase en la manera de aprehender simbólicamente la alimentación ética, y si dicha alimentación tiene sentido para los individuos de distintas categorías sociales. Estudian la forma en que los discursos sociales modelan las prácticas alimentarias y para ello recurren primero al concepto de «repertorio cultural» (Lamont, 1992; Tilly, 1993; Swidler, 1986, 2001), que toman prestado de la sociología de la cultura (desarrollo del concepto de «repertorio de la alimentación ética») y que permite dar cuenta de la manera "creativa en que los individuos emplean a diario elementos sacados de este discurso» sobre la ética. Las autoras recurren luego al concepto de "fronteras simbólicas» que llevan al individuo a trazar límites para distinguirse y manifestar su pertenencia a un grupo, todo ello en la línea de los trabajos de Durkheim y Mauss (1903), Becker (1963) y Douglas (1966). Contrastada con los discursos de individuos pertenecientes a diferentes entornos sociales, esta doble conceptualización permite afirmar que los privilegios económicos y culturales favorecen el acceso al repertorio dominante de la alimentación ética mientras las personas de entornos sociodemográficos y étnicos populares, o incluso marginales, tienen menos acceso a este repertorio. Así, las personas blancas procedentes de la clase media recurren en mayor medida al repertorio de la alimentación ética. No obstante, en una segunda parte, el estudio de los hábitos de alimentación diaria muestra las diferencias que pueden darse entre el reconocimiento legítimo del discurso ético sobre la alimentación y la puesta en práctica. Por un lado, los privilegios culturales y económicos permiten ciertamente acceder al repertorio dominante, pero «no garantizan un elevado grado de implicación» en la práctica. Para un gran número de personas de entornos favorecidos, independientemente de estar o no implicadas en la alimentación ética, son sobre todo los comportamientos alimentarios globales considerados «sanos» los que actúan como marcador y, por extensión, como factor de distinción cultural. Sin embargo, el hecho de que los grupos marginados estén menos implicados en la alimentación ética no significa que «no les afecten los dilemas morales relacionados con las opciones alimentarias». Para las autores, este resultado es clave ya que respalda los trabajos que rechazan la tesis de la insuficiencia moral de las clases populares según la cual éstas desconocen la problemática moral ligada a la alimentación, o ni siquiera les preocupa o no se implican en ello (Johnston, Szabo y Rodney). 


\section{La alimentación como factor de identidad nacional, e incluso nacionalista}

10 Mientras algunos gustos alimentarios son fuertes marcadores sociales dado que diferencian a las clases sociales, otros adquieren el estatus de "patrimonio nacional», de bien común, y se convierten en emblemas, en marcadores culturales que trascienden las diferencias de clase. Así, podemos estudiar la alimentación como un vector de identidad (Pilcher, 1998; Thiesse, 1999; Bruegel y Lauriaux, 2002). A igual que en la investigación europea (Poulain, 1997, 2000, 2005; Espeitx, 2008; Bessière y Tibère, 2010), del otro lado de Atlántico, algunos investigadores han estudiado la patrimonialización de las cocinas latinoamericanas -los hábitos alimentarios se consideran así «patrimonio cultural» y soporte de identidad nacional (Florescano, 1993; Álvarez, 2002; Cottom, 2004, 2007; Álvarez y Medina, 2008; Moncusí y Santamarina, 2008; Zapata, 2008)- a pesar de que la investigación en este campo en América Latina es aún incipiente (Bak-Geller y Katz, 2011).

La celebración del bicentenario de la independencia de los países latinoamericanos fue una excelente ocasión para reflexionar sobre la importancia que tiene la alimentación en las sociedades sudamericanas. En aquella ocasión vimos cómo se ensalzaron los platos nacionales de diferentes países. Sin embargo, pocos estudios analizan con suficiente detenimiento la manera en que, precisamente, esos platos contribuyen a definir la identidad nacional de los países latinoamericanos en los albores del siglo XXI. Con todo, resulta interesante ver cómo la identidad nacional se construye a la luz del pasado y, en mayor medida, en relación con el extranjero. De norte a sur, las diversas formas de alimentación que definen las cocinas nacionales tienen una relación de rechazo o atracción respecto a lo internacional. México, por ejemplo, no ceja en reclamar su pasado precolombino para construir la «cocina mexicana» pese a que ésta no ha existido como tal antes del siglo XX en la medida en que es el resultado de la fusión de diversos elementos y técnicas exógenas y endógenas (Pilcher, 1998). En el lado opuesto, Argentina rechaza su pasado y solo define su cocina a través de sus fuertes vínculos con el extranjero, como resultado evidente de la inmigración europea reciente. Ello se traduce en un cierto cosmopolitismo de la cocina argentina (Pilcher, 2012), al menos en la región de La Pampa (Milanesio).

\section{De una difusión de arriba abajo...}

12 En algunos casos, este bien común nacional -e incluso patrimonial- como construcción social se convierte a veces en soporte y herramienta de la propaganda nacionalista y en objeto de propaganda política. La alimentación puede servir por tanto para unir a un pueblo, por cuanto se erige en emblema nacional y soporte de una política ideológica fuerte con fines nacionalistas. Es lo que muestra precisamente Natalia Milanesio en su estudio sobre el papel que tuvo la producción y el consumo de carne en la propaganda peronista (del ex presidente argentino, Juan Domingo Perón). En su análisis de los aspectos culturales e institucionales característicos de la política alimentaria peronista de los años 50, la autora recurre al concepto de «virtuosismo semiótico» de la alimentación desarrollado por el antropólogo Arjun Appadurai (1988) -esto es, la capacidad del signo cultural de transmitir mensajes múltiples- para actualizar mejor los roles y la utilización ideológica que hace el Estado del consumo alimentario y 
particularmente, las implicaciones simbólicas del consumo de carne en su política alimentaria. Como la autora señala en su conclusión, «la política bovina del peronismo antes de 1950 va más allá del simple aumento del consumo por persona: dicha política redefine la imagen de Argentina en el seno de la economía mundial, valida el concepto de autodeterminación económica y cuestiona, al menos a nivel discursivo, el papel del capitalismo internacional». Considerada tradicionalmente como un alimento de lujo, la carne debía simbolizar el acceso de las clases populares a nuevos bienes y, por tanto, a un nuevo espacio en la sociedad. La política peronista contribuyó así a difundir el consumo de carne con fines políticos: preferir a los consumidores nacionales en detrimento de los mercados exteriores para favorecer la difusión de una poderosa ideología de soberanía económica a través de la política bovina.

Aparte de los intereses políticos y electoralistas (algunos asociados al populismo), la erección de la carne como emblema nacional sirvió para redefinir los roles masculino y femenino tradicionales: «cocinados desde siempre por mujeres, los platos recomendados por el gobierno peronista reafirmaban el papel esencial de la mujer en la construcción de la identidad culinaria nacional, un movimiento alejado de la figura masculina del asador». Porque, tradicionalmente, los hombres solo intervenían en la cocina para hacer carne asada.

Con este ejemplo puede entenderse cómo la difusión vertical hacia las clases populares de ciertos platos -claros marcadores de clase social ya que generalmente se limitan a las élites- permite asentar una política general nacionalista. Ahora bien, la cuestión de la difusión de gustos es fundamental en la sociología de la alimentación ya que obliga a concebir el espacio y la diferenciación social de forma dinámica y no estática. Algunos grupos sociales imitan ciertas especificidades propias de otros grupos. Otros trabajan en la difusión de su modelo alimentario en nombre de un principio político, como acabamos de ver en el ejemplo de la política peronista. Sin embargo, la difusión de modelos y gustos alimentarios también trasciende las fronteras simbólicas entre clases (Milanesio; García Garza; Pilcher; Johnston y Bauman, 2010), por lo que puede entenderse hasta qué punto la alimentación dista de ser anodina y, menos aún, neutra políticamente. Desde el momento en que la alimentación concierne a todos los individuos y que el Estado se encarga de garantizar las condiciones para acceder a ella, además de una cierta calidad (Stanziani, 2005) para preservar la salud de la población, dicha alimentación se convierte en una cuestión política.

\section{... a una difusión de abajo a arriba}

15 Pero esta difusión vertical se realiza también de abajo a arriba. Domingo García Garza lo demuestra en su artículo sobre la difusión de prácticas populares a partir del caso de los tacos en la ciudad mexicana de Monterrey. Considerados inicialmente como un producto popular, los tacos (tortillas de maíz enrolladas con algún alimento en su interior) se extendieron por todo el espacio social a partir de los años 90, adaptándose a los gustos y modos de consumo de diferentes círculos, en especial, de las clases altas. Pese a que su consumo se ha generalizado en toda la sociedad, los elementos que diferencian a los grupos sociales se mantienen. García Garza demuestra cómo este «aburguesamiento» de platos y prácticas populares solo ha sido posible a costa de un aumento de la gama y una recontextualización en un marco más conforme con las normas de la restauración clásica. Esta operación ha sido posible en la medida en que esta imagen revalorizada de los tacos contribuye a definir la identidad nacional. Pero 
esta contribución se explica también por el hecho de que estas prácticas remiten a los conceptos de terroir y autenticidad, sobre todo cuando se utilizan productos hoy considerados «gourmets». Productos de antaño devaluados, los tacos de insectos, de saltamontes o de huitlacoche (hongo comestible, parásito del maíz y considerado como equivalente al caviar en México) se han convertido hoy día en fuente de orgullo nacional y de distinción social, principalmente para las élites, algo que lleva a redefinir la legitimidad de los platos populares y, en consecuencia, la jerarquía de los alimentos en México.

\section{Difusión y metamorfosis de los gustos entre países}

16 Si bien los casos estudiados hasta ahora plantean de forma más o menos explícita la cuestión de la difusión y la circulación de los modos alimentarios entre grupos sociales en un contexto nacional, dicha cuestión se plantea explícitamente en el caso de la circulación transfronteriza de bienes alimentarios. Esta problemática y, en concreto, la difusión de modelos alimentarios a escala mundial y su apropiación o no por las culturas nacionales, ha sido objeto de numerosos debates tanto en Europa como en Estados Unidos. Así, a la tesis de la «McDonalización» de la sociedad, formulada a principios de los años 90 (Ritzer, 1993) y ampliamente criticada en la actualidad, se contrapone la tesis de la «era de la producción a medida para las masas» (Taylor, Smith y Lyon, 1998): la difusión de formas alimentarias extranacionales exige una cierta conformidad con los hábitos de consumo locales. En esta perspectiva, es la dimensión nacional, es decir local, que sirve de punto de observación: el investigador trata de entender cómo los estilos alimentarios extranacionales importados son o no adoptados a escala del territorio nacional.

\section{El peso del contexto nacional en la difusión de modelos internacionales}

17 Una de las claves es primero entender cómo un espacio nacional gestiona a la vez tradiciones locales y nacionales en un contexto de fuerte difusión de las prácticas transnacionales a escala mundial. Precisamente, la cuestión de la relación entre lo local y lo global se aborda en el artículo de Jeffrey Pilcher con respecto a tres países latinoamericanos (Argentina, Cuba y México). En una perspectiva histórica, Pilcher estudia la interacción entre prácticas locales e internacionales y muestra cómo lo local y lo global están fuertemente imbricados. Esta imbricación varía sin embargo según los contextos nacionales: las prácticas culinarias criollas (esto es, desarrolladas en las nuevas repúblicas que surgen tras la fragmentación del imperio español) se reivindican más o menos dependiendo de los recursos disponibles, de la veteranía como país independiente, de la relación con lo internacional y, por último, de las problemáticas políticas internas de cada país. Comer «criollo» está más consolidado en Cuba y México (pese a que el término ha sido desterrado del vocabulario) que en Argentina.

Los trabajos iniciados por Pilcher desde hace unos diez años, desconocidos en cierto modo en Francia, muestran que la cocina y la identidad nacional se definen respecto a los principales modelos culinarios encarnados por los países que han servido de modelo de sociedad para América Latina (en este caso, Francia, España e Inglaterra). Pilcher apunta que comer «a la criolla» supone en definitiva adaptar los platos europeos a los 
ingredientes disponibles y al carácter local. Sin embargo, esto no se hace ni del mismo modo ni con los mismos ingredientes, tanto menos cuanto que la relación que los tres países mantienen con sus antiguos imperios coloniales varía de uno a otro. El interés de este enfoque comparativo entre distintos países estriba en mostrar cómo los mecanismos de difusión y de integración de nuevos alimentos, platos o estilos alimentarios, de lo global a lo local, deben analizarse respecto a los contextos nacionales y al mantenimiento de ciertas especificidades locales. Pilcher describe el modo en que tres tradiciones culinarias, lejos de oponerse a la globalización, combinan el patriotismo y el cosmopolitismo dando origen a las nuevas cocinas nacionales o criollas. Las cocinas de México, Cuba y Argentina son, cada una a su manera, emblemáticas de este proceso de sincretismo culinario llevado a cabo a finales del siglo XIX. Al estudiar la difusión del modelo criollo en la literatura y las prácticas culinarias en Argentina, Cuba y México, Pilcher presenta la articulación entre ambos niveles. Mientras en Cuba el término "criollo» ha terminado englobando a los productos alimentarios locales incluidos en la categoría de «viandas» (tubérculos como la mandioca, la patata, la batata, etc.), en Argentina, el término criollo abarca más productos locales (desde, por ejemplo, especialidades hispanas como las empanadas y los pucheros a las sopas de calabaza y de maíz nativo). En México, por el contrario, el término "criollo/a» apenas está integrado. El país ha desarrollado estas mismas prácticas culinarias, adaptándolas al clima político de la época y a los gustos locales. La cocina criolla siempre ha existido en México pero no tiene esa denominación porque allí el término «criollo» ha conservado su antigua acepción (designa a los españoles nacidos en México) cargada de connotaciones y, por tanto, mal aceptada por los mexicanos, fuertemente impregnados de nacionalismo. De este modo, México ha suprimido los elementos originales y la influencia española de la cocina mexicana al eliminar ciertos términos para referirse a ella. Las élites mexicanas que, por lo general, son de origen europeo, invocan la herencia de los aztecas y de su patrimonio culinario. No obstante, reivindican la cocina mexicana y sus orígenes precolombinos, excluyendo y marginando a los pueblos indígenas de la sociedad contemporánea. Las élites por tanto se han apropiado del pasado indígena para forjar una cocina nacional y colarse en el proceso de occidentalización. Esto se ha realizado a costa de desvincular de la cocina criolla a los indígenas que la crearon y de borrar las huellas europeas. Todo ocurre como si hubiera que deshacerse del origen extranjero de las prácticas culinarias para forjar un carácter nacional. Es, en cierto modo, una manera de de cortar con un (doloroso) pasado para inventar un presente más conforme con los ideales nacionalistas surgidos tras la Revolución (1910-20).

\section{La alimentación frente a la inmigración}

Junto a esta perspectiva sociohistórica existen otros enfoques más etnográficos, mayormente centrados en analizar los mecanismos de circulación de los bienes alimentarios en un contexto de inmigración entre países, en particular, de países latinoamericanos hacia Estados Unidos. Una de las principales cuestiones en la que nos detendremos y que subyace en los dos artículos que se presentan aquí estriba en saber en qué condiciones sociales los inmigrantes sudamericanos en Estados Unidos mantienen los hábitos alimentarios de sus países de origen o desarrollan otros. Se trata no solo de descifrar cómo en un territorio nacional se adoptan modelos extraterritoriales, sino también de entender cómo y en qué condiciones se perpetúan 
los hábitos locales en un contexto de movilidad internacional. A este respecto pueden adelantarse varias respuestas.

Una de las pistas apunta precisamente a las circunstancias que intervienen desde el punto de vista identitario en la circulación de bienes alimentarios. En los dos ejemplos presentados aquí, el alimento funciona como un «instrumento de recuerdo identitario» que en cierto modo va más allá del alimento en sí mismo. Así, Maximino Matus analiza en su artículo las estrategias empleadas por colectivos de distribuidores y comerciantes para introducir alimentos de forma clandestina entre Estados Unidos y diversos países latinoamericanos (y a la inversa) y ello, para satisfacer y responder a la «nostalgia de un migrante por el sabor, [el] olor y [la] textura de un alimento». En efecto, al tiempo que es frecuente encontrar en Estados Unidos comercios y restaurantes que venden productos y alimentos de países latinoamericanos -esto es, países de los que son originarios los inmigrantes- también es habitual encontrar en estos países comercios y restaurantes cuyos productos provienen de otros países del mundo. De este modo, Matus se propone dibujar lo que llama "paisajes alimentarios híbridos». Según este autor, la diversidad en la inmigración dentro de los países de América Latina y entre América Latina y Estados Unidos hace que se den hibridaciones de las prácticas alimentarias de los migrantes, que afectan no solo a los migrantes en el espacio de destino sino también sus comunidades de origen. El caso del municipio de Oxcutzcab lo ilustra muy bien: en esta ciudad del sureste de México es común encontrar restaurantes asiáticos, italianos, franceses y estadounidenses. Según Matus, el desarrollo de estas ofertas alimentarias «híbridas» tiene que ver con la demanda de los migrantes, de Estados Unidos sobre todo, vinculada con una cierta nostalgia ligada a los nuevos hábitos alimentarios desarrollados en el país receptor. Esto es precisamente lo que estudia Frida CalderónBony: la nostalgia de los hábitos alimentarios que experimentan los inmigrantes originarios de la comuna mexicana de Patamban e instalados en Estados Unidos. En su análisis, la autora trata de entender qué lugar ocupa la alimentación en la dinámica identitaria ligada a la migración y destaca cómo, también en este caso, los inmigrantes mantienen un fuerte apego a ciertos hábitos alimentarios. Los bienes alimentarios se convierten en productos que circulan entre sus países de origen y su nuevo país de acogida (o en sentido inverso, cuando envían alimentos a sus familias en sus países de origen). Con todo, una de las comprobaciones empíricas realizadas por la autora tiene que ver con la naturaleza misma del apego de los inmigrantes a algunos platos de sus países de origen: la nostalgia (Camou, 1994; Pilcher, 2012).

21 La segunda argumentación tiene que ver con el desarrollo en Estados Unidos de una oferta alimentaria del país de origen y de los mercados de productos alimentarios de los países del sur. Calderón-Bony analiza en este sentido el «mercado de la nostalgia» en la línea de Hirai (2009) en el contexto de la inmigración mexicana en Estados Unidos. El mercado de la nostalgia es un concepto a partir del cual «se busca definir el vínculo existente entre la apertura por parte de un migrante de un comercio de productos mexicanos como actividad económica y la oferta de productos que sirven para identificarse con la cultura mexicana», ya sean tiendas (dedicadas únicamente a la venta de productos comestibles como latas de conserva de diferentes tipos de ají, granos de maíz para preparar pozole, tortillas y tostadas, hojas de maíz para preparar tamales, queso fresco, etc.) o comercios más importantes que se asemejan más a supermercados. La inmigración se convierte así en el soporte para que surja una nueva oferta alimentaria en el territorio receptor de los inmigrantes mexicanos. Matus, que llega a las mismas conclusiones, muestra que 
paralelamente a esta oferta se desarrollan «mercados clandestinos». Ciertamente, si bien la circulación de alimentos parece realizarse entre países del sur para alimentar un mercado con una fuerte demanda, la cuestión es más complicada para los productos con destino a Estados Unidos dadas las fuertes restricciones sanitarias impuestas a los productos que entran en territorio estadounidense. Dada la fuerte demanda de productos alimentarios procedentes de los países de origen de los inmigrantes, el autor analiza cómo los actores (especialmente, los comerciantes) esquivan lo que él mismo llama «políticas persecutorias» estadounidenses cuyo objetivo es excluir ciertos productos del país. Matus habla así de la aparición de un mercado clandestino de algunos productos alimentarios (por ejemplo, de Oaxaca a Los Ángeles, pasando por Tijuana). El desarrollo de estos mercados clandestinos parece en parte satisfacer la nostalgia alimentaria de los inmigrantes, ya estén instalados o no en Estados Unidos.

Sin embargo, el hecho de disponer de comercios in situ no impide que los inmigrantes reciban alimentos de sus familias que viven en el país de origen. Así, además del desarrollo de mercados oficiales y de otros que lo son menos, existe una circulación que podríamos considerar «privada» al estar inscrita dentro de las redes familiares. Es lo que describe perfectamente Calderón-Bony a propósito de la circulación de bienes alimentarios. La autora destaca primero que los alimentos circulan en sentido inverso (del país de origen al país receptor) a como lo hacen otros bienes como el dinero (del país de acogida al país de origen). Por otra parte, como afirma la autora, «la circulación de los alimentos entre el pueblo y Estados Unidos permite fomentar la proximidad y consolidar los vínculos (familiares y de amistad), al tiempo que estos alimentos ayudan a "digerir" la distancia». Este elemento es clave ya que subyace en él la idea del mana propuesta por Marcel Mauss (1924) y según la cual, en el intercambio, con la cosa circula el «espíritu de la cosa» dada. En este sentido podemos entender que el «plato hecho aquí» no es nunca exactamente el mismo que «el plato hecho allá» porque lo que circula, más que el alimento, es el espíritu ligado al alimento, el de la familia. Aquí, el intercambio permite mantener el apego del inmigrante a sus compatriotas. ¿Es la nostalgia el espíritu mismo de la cosa, el mana? o bien, por decirlo de otro modo: no comemos alimentos porque sentimos nostalgia de ellos sino que sentimos nostalgia cuando los comemos.

El último argumento tiene que ver con el hecho de que los inmigrantes adoptan los nuevos hábitos propios del territorio receptor, forjando una identidad entre aquí y allá. Si bien este punto de vista es presentado de forma más o menos implícita en el texto de Matus a través del concepto de alimentación híbrida (que presupone la yuxtaposición de modos alimentarios mediante integración múltiple ligada a la trayectoria migratoria), dicho enfoque es central en el análisis realizado por Calderón-Bony sobre la importancia que ocupa la alimentación. Para esta autora, en el caso de los inmigrantes estudiados también se da una apropiación de la cultura alimentaria estadounidense. No se trata de oponer «mantenimiento» de hábitos ligados al país de origen y «cambio» vinculado con el país de acogida, sino de analizarlos de forma dialéctica y dinámica como soporte de una dinámica identitaria. Aquí, la alimentación es un soporte identitario de la inmigración dado que permite mantener el vínculo con el país, la región, el pueblo o la familia y, al mismo tiempo, integrar nuevos valores relacionados con la cultura receptora. No se trata en ningún caso de revisar la problemática de la integración/asimilación: el interés del artículo reside en el hecho de mostrar hasta qué punto la identidad es ciertamente un proceso dinámico en el que se incluye la alimentación. Ahora bien, desde el momento en que la autora habla de esta 
dimensión dinámica del proceso identitario a través de la alimentación mediante la integración de nuevos modos alimentarios propios del país de acogida, está planteando la tradicional problemática de la difusión de modelos alimentarios en la sociedad. El interés de su trabajo reside en integrar una dimensión generacional en la comprensión del proceso de difusión de los modelos alimentarios en la familia inmigrante. CalderónBony muestra así que son los niños los vectores y transmisores de los nuevos hábitos alimentarios que vienen no a competir con los hábitos de origen sino a completarlos, e incluso a redefinirlos.

En conclusión, todas las contribuciones a este tercer número demuestran el gran número de problemáticas y planteamientos que actualmente se manejan en el campo de las ciencias sociales en torno al estudio de la alimentación en las Américas. Dichas contribuciones destacan el interés heurístico de los problemas teóricos y empíricos que contribuyen al diálogo y al intercambio entre disciplinas, por un lado, y entre países y continentes, por otro, e invitan a prolongar el diálogo Norte/Sur con otros países, sobre otros objetos que al igual que la movilidad, la circulación y la inmigración están en el centro mismo de la historia de las sociedades humanas.

\section{BIBLIOGRAFÍA}

ÁLVAREZ Marcelo, «El gusto es nuestro. Modelos alimentarios y políticas de patrimonialización», Catauro: Revista Cubana de Antropología, n 5, 2002, pp. 61-78.

ÁLVAREZ Marcelo y MEDINA Francisco Xavier (eds.), Identidades en el plato. El patrimonio cultural alimentario entre Europa y América, Barcelona, Icaria, 2008.

APPADURAI Arjun, «How to Make National Cuisine: Cookbooks in Contemporary India», Comparative Studies in Society and History, vol. 30, n 1, 1988, pp. 3-24.

BABB Florence, «From the Field to the Cooking Pot: Economic crisis and the threat to marketers in Peru», Ethnology, vol. 26, n. 2, 1987, pp. 137-149.

BAK-GELLER Sarah y KATZ Esther, «Semana de Estudios de Cocina y Alimentación en América Latina», Guadalajara (México), Congreso Internacional "De los primeros recetarios nacionales a las cocinas patrimoniales: 200 años de nacionalismo culinario en América Latina”, 12-15 sept., 2011.

BAUER Arnold J., Good, Power, History: Latin America's Material Culture, Cambridge, Cambridge University Press, 2001.

BAUMAN Shyon y JOHNSTON Josée, «Democracy versus Distinction: A Study of Omnivorousness in Gourmet Food Writing», American Journal of Sociology, vol. 13, n 1, 2007, pp. 165-204.

BECKER Howard, Outsiders: Studies in the Sociology of Deviance, New York, The Free Press, 1963.

BERTRÁN Miriam, «Acercamiento antropológico de la alimentación y salud en México», Phycis, Revista de Saúde Coletiva, vol. 20, n² 2, 2010, pp. 387-411.

BESSIÈRE Jacinthe y TIBÈRE Laurence, « Éditorial : Patrimoines alimentaires », Anthropology of Food, $n^{\circ} 8,15$ de junio, 2010. Disponible en línea: http://aof.revues.org/6782. 
BOURDIEU Pierre, La distinción. Criterio y bases sociales del gusto, Madrid, Taurus, 1998.

BOURDIEU Pierre y SAINT MARTIN (de) Monique, «Anatomía del gusto», Actes de la recherche en sciences sociales, $\mathrm{n}^{\circ}$ 5, 1976, pp. 2-81.

BOURGUES Héctor, BENGOA José y O'DONNELL Alejandro (eds.), Historias de la Nutrición en América Latina, México, SLAN, 2009.

BRAUDEL Fernand, Civilización material, economía y capitalismo, siglos XV-XVIII, Alianza Editorial, 2005.

BRUEGEL Martin y LAURIAUX Bruno (dirs.), Histoire et identités alimentaires en Europe, Paris, Hachette, 2002.

CAMOU Ernesto, «La nostalgia del rancho: Notas sobre la cultura urbana y la carne asada» in Shoko DOODE y Emma Paulina PÉREZ (dirs.), Sociedad, economía y cultura alimentaria, Hermosillo, CIAD/CIESAS, 1994, pp. 421-429.

CARDON Philippe, « Regard sociologique sur les pratiques alimentaires des personnes âgées vivant à domicile «, Gérontologie et société, n 134, 2010, pp. 31-42.

CARDON Philippe, « Manger en vieillissant pose-t-il vraiment problème ? Veuvage et transformations de l'alimentation des personnes âgées «, Lien Social et Politiques, n 62, 2009a, pp. 85-95.

CARDON Philippe, « Retraite et alimentation : les effets de la mobilité «, Recherches familiales, $n^{\circ} 6$, 2009b, pp. 105-115.

CARDON Philippe y GOJARD Séverine, «Les personnes âgées face à la dépendance culinaire : entre délégation et remplacement ", Retraite et société, n56, 2009, pp. 169-193.

CARRASCO Noelia, «Desarrollos de la antropología de la alimentación en América Latina: hacia el estudio de los problemas alimentarios contemporáneos», Estudios Sociales, vol. 16, n 30, 2007, pp. 79-102.

CASCUDO Luis da Camara, História da alimentação no Brasil, São Paulo, Universidade de São Paulo, 1983.

CHAVES Mônica, «La restauration hors foyer dans l'État brésilien de Minas Gerais», Journal des Anthropologues, $\mathrm{n}^{\circ}$ 106-107, 2006, pp. 189-204.

COLE Nicki, «Global capitalism organizing knowledge of race, gender and class: The case of socially responsible coffee», Race, Gender and Class, vol. 15, n 1-2, 2008, pp. 170-187.

CONTRERAS Jesús y GRACIA Mabel, Alimentación y Cultura. Perspectivas antropológicas, Barcelona, Ariel, 2005.

CORBEAU Jean-Pierre y POULAIN Jean-Pierre, Penser l'alimentation. Entre imaginaire et rationalité, Paris, Privat, 2002.

CORBEAU Jean-Pierre (coord.), Cuisine, alimentation, métissage, Paris, Bastidiana, 2000.

СОТТОМ Bolfy, «El patrimonio cultural como problema interdisciplinario», Red Patrimonio: Revista digital de estudios en patrimonio cultural, 2007a.

COTTOM Bolfy, «Diversidad y enfoques del patrimonio cultural», Cuadernos del Patrimonio Cultural y Turismo, $\mathrm{n}^{\circ} 8,2004$.

DONNAT Olivier y TOILA Paul (dirs), Le(s) public(s) de la culture, Paris, Presses de Sciences Po, 2003. 
DONNAT Olivier, Les français face à la culture. De l'exclusion à l'éclectisme, Paris, La Découverte, coll. «Textes à l'appui», 1994.

DOUGLAS Mary, «Les structures du culinaire», Communications, vol. 31, 1979, pp. 145-170.

DURKHEIM Émile y MAUSS Marcel, «De quelques formes primitives de classification. Contribution à l'étude des représentations collectives», Année sociologique, nº 6, 1903.

DUVAL Julien, «Distinction studies», Actes de la recherche en sciences sociales, $n^{\circ}$ 181-182, 2010, pp. 146-156.

ELOY Florence y PALHETA Ugo, «Cultures juvéniles et enseignement musical au collège», Revue française de pédagogie, $\mathrm{n}^{\circ}$ 163, 1 de junio, 2008. Disponible en línea: http://rfp.revues.org/957.

ELOY Florence, Apprendre à écouter la musique. Culture légitime, culture scolaire et cultures juvéniles, Paris, EHESS, tesis dirigida por Dominique Pasquier, 2012.

ESPEITX Elena, «Los sentidos del patrimonio alimentario en el sur de Europa» in Marcelo ÁLVAREZ y Francisco-Xavier MEDINA (eds.), Identidades en el plato. El patrimonio cultural alimentario entre Europa y América, Barcelona, Icaria, 2008, pp. 45-62.

FERNÁNDEZ ARMESTO Felipe, Historia de la comida: Alimentos, cocina y civilización, Tusquets Editores S.A., 2004.

FISCHLER Claude y MASSON Estelle, Manger. Français, Européens et Américains face à l'alimentation, Paris, Odile Jacob, 2007.

FLANDRIN Jean-Louis y MONTANARI Massimo, Histoire de l'alimentation, Paris, Fayard, 1996.

FLORES Jesús, Breve historia de la comida mexicana, México, De Bolsillo, 2003.

FLORESCANO Enrique (coord.), El patrimonio cultural de México, México, FCE, 1993.

FREYRE Gilberto, Casa grande e senzala. Formação da familia brasileira sob o regime de economia patriarcal, Rio de Janeiro, Maia e Schmidt, 1933.

GABACCIA Donna, We are what we eat. Ethnic Food and the Making of the Americans, Boston, Harvard University Press, 1998.

GARNSEY Peter, Food and Society in Classical Antiquity, Cambridge, 1999.

GARCÍA GARZA Domingo, «Una etnografía económica de los tacos callejeros en México. El caso de Monterrey», Estudios Sociales, vol. 19, n 37, 2011, pp. 32-63. Disponible en línea: http:// www.redalyc.org/articulo.oa?id=41716750002.

GARCÍA GARZA Domingo, «Prácticas alimenticias y clasificación social. ¿Los tacos son un alimento 'popular'?», Civitas, vol. 10, n 3, 2010, pp. 430-449. Disponible en línea: http:// revistaseletronicas.pucrs.br/ojs/index.php/civitas/article/viewFile/7464/5970.

GARCÍA GARZA Domingo, L'entreprenariat informel. Le cas des marchands de tacos à Monterrey (Mexique), Paris, EHESS, tesis dirigida por Rémi Lenoir, 2009.

GOJARD Séverine, Le métier de mère, Paris, La Dispute, coll. «Corps santé société», 2010. GOODY Jack, Cooking, Cuisine and Class, London, Cambridge University Press, 1982.

GRIGNON Claude y GRIGNON Christiane, «Styles d'alimentation et goûts populaires», Revue française de sociologie, 1980, vol. 21, pp. 531-569.

HERPIN Nicolas y VERGER Daniel, Consommation et modes de vie en France. Une approche économique et sociologique sur un demi-siècle, Paris, La Découverte coll. » Grands Repères », 2008. 
HIRAI Shinji, Economía política de la nostalgia: un estudio sobre la transformación del paisaje urbano en la migración transnacional entre México y Estados Unidos, México, UAM/Juan Pablos Editor, 2009.

LAMONT Michèle, Money, Morals, and Manners: The Culture of the French and the American UpperMiddle Class, Chicago, University of Chicago Press, 1992.

LÉVI-STRASS Claude, Mythologiques, Paris, Plon, (4 volumes), 1964.

LONG-SOLIS Janet y VARGAS Luis, (eds.), Food Culture in Mexico, Westport/London, Greenwood Press, coll. «Food Culture Around the World», 2005.

MONCUSÍ Albert y SANTAMARINA Beatriz, «Bueno para comer, bueno para patrimonializar. La propuesta de la cocina mexicana como Patrimonio Inmaterial de la Humanidad» in Marcelo ÁLVAREZ y Francisco-Xavier MEDINA (eds.), Identidades en el plato. El patrimonio cultural alimentario entre América y Europa, Barcelona, Icaria, 2008, pp. 127-142.

MAGALHãES (de) Sônia M., A Mesa de Mariana: Produção e consumo de alimentos em Minas Gerais (1750-1850), São Paulo, Annablume/Fapesp, 2004.

MARTÍNEZ Irma y VILLEZCA Pedro, «La alimentación en México. Un estudio a partir de la encuesta nacional de ingresos y gastos de los hogares», Notas: Revista de información y análisis (INEGI), 2003, pp. 26-37.

MINTZ Sidney, Tasting food, Tasting Freedom: Excursions into Eating, Culture, and the Past, Boston, Beacon Press, 1996.

MINTZ Sidney y DUBOIS Christine, «The Anthropology of Food and Eating», Annual Review of Anthropology, $\mathrm{n}^{\circ}$ 31, 2002, pp. 99-119.

ORTIZ Ana Silvia, VÁZQUEZ Verónica y MONTES Margarita, «La alimentación en México. Enfoques y visión de futuro», Estudios Sociales, vol. 13, n 25, 2005, pp. 8-34.

OSEGUERA David, «La comida. Lugar de encuentro entre disciplinas científicas», Estudios sobre las culturas contemporáneas, vol. $7, \mathrm{n}^{\circ} 13,2001, \mathrm{pp} .141-151$.

PETERSON Richard, «Understanding audience segmentation: from elite and mass to omnivore and univore», Poetics, n 32, 1992, p. 169-194.

PETERSON Roger y KERN R.M., «Changing highbrow taste: from snob to omnivore», American Sociological Review, vol. 61, n 5, 1996, pp. 900-907.

PILCHER Jeffrey M., Que vivan los tamales! Food and the Making of the Mexican Identity, Albuquerque, University of Mexico Press, 1998.

PILCHER Jeffrey M., Planet Taco: A Global History of Mexican Food, New York, Oxford University Press, 2012.

POULAIN Jean-Pierre (dir.), Dictionnaire des cultures alimentaires, Paris, PUF, 2012.

POULAIN Jean-Pierre, «French gastronomie, french gastronomies» in Dara GOLDSTEIN y Kathrin MERKELE (eds.), Culinary cultures of Europe Identity, Diversity and Dialogue, Estrasburgo, Ediciones del Consejo de Europa, 2005, pp. 157-170.

POULAIN Jean-Pierre, Sociologies de l'alimentation. Les mangeurs et l'espace social alimentaire, Paris, PUF, coll. « Sciences sociales et sociétés «, 2002.

POULAIN Jean-Pierre, Manger aujourd'hui : attitudes normes et pratiques, Toulouse, Privat, 2001. 
POULAIN Jean-Pierre, «Les patrimoines gastronomiques et leurs valorisations touristiques» in Rachid AMIROU y Philippe BACHIMON, Le tourisme local, une culture de l'exotisme, L'Harmattan, 2000, pp. 157-183.

POULAIN Jean-Pierre, «Le gout du terroir à l'heure de l'Europe», Ethnologie française, vol. 27, 1997, pp. 18-26.

RITZER George, The MacDonaldization of Society: An Investigation Into the Changing Character of Contemporary Social Life, London, Sage, 1993.

STANZIANI Alessandro, Histoire de la qualité alimentaire XIX ${ }^{e}-X X^{e}$ siècles, Paris, Seuil, coll. « Liber », 2005.

SUREMAIN (de) Charles-Édouard y KATZ Esther, «Modelos alimentarios y recomposiciones sociales en América Latina», Anthrolpology of Food, 20 de diciembre de 2009. Disponible en línea: http://aof.revues.org/6432.

SWIDLER Ann, Talk of Love: How Culture Matters, Chicago, University of Chicago Press, 2001.

TAYLOR Stephen, SMITH Shenna y LYON Phil, «McDonalization and consumer choice in the future: an illusion or the next marketing Revolution?» in Mark ALFINO, John S. CAPUTO y Robert WYNYARD (eds.), Mcdonaldization Revisited. Critical Essays on Consumer Culture, Westport/London, Prager Publishers, 1998, pp. 105-119.

THIESSE Anne-Marie, La création des identités nationales. Europe XVII ${ }^{e}-X X^{e}$ siècles, Paris, Seuil, 1999.

TILLY Charles, «Contentious repertoire in Great Britain, 1758-1834», Social Science History, vol. 17, $\mathrm{n}^{\circ} 20$, pp. 253-280.

TINKER Irene, Street Food. Urban Food and Employment in Developing Countries, Oxford, Oxford University Press, 1997.

TORRES Felipe y TRAPAGA Yolanda (eds.), La alimentación de los mexicanos en la alborada del tercer milenio, México, UNAM, 2001.

VARGAS Luis A., «Antropología y alimentación», Antropológicas, n 7, 1993, pp. 22-23.

ZAPATA Sergio, «Patrimonialización de la gastronomía peruana y planteamiento de un proyecto de desarrollo» in Marcelo ÁLVAREZ y Francisco-Xavier MEDINA (eds.), Identidades en el plato. El patrimonio cultural alimentario entre América y Europa, Barcelona, Icaria, 2008, pp. 153-174.

\section{AUTORES}

\section{PHILIPPE CARDON}

Maître de conférences en sociologie, Université Lille 3. Chercheur au laboratoire Ceries (laboratoire de recherche individus-épreuves et société) / Université Lille 3. Chercheur associé au laboratoire ALISS (Alimentation et sciences sociales)/INRA.

Philippe.Cardon@ivry.inra.fr

\section{DOMINGO GARCIA-GARZA}

Maître de conférences en civilisation latino-américaine (Université Charles de Gaulle). Chercheur au CECILLE (Lille 3) et chercheur associé au CESSP (EHESS/Paris 1/CNRS).

domingo.garciagarza@univ-lille3.fr 